\title{
PENGEMBANGAN E-MODUL INTERAKTIF UNTUK DISCOVERY LEARNING PADA PEMBELAJARAN MEKANIKA TEKNIK DAN ELEMEN MESIN
}

\author{
Marko Ayaki Lumbantobing ${ }^{1}$, Sudji Munadi ${ }^{2}$, Bernardus Sentot Wijanarka ${ }^{3}$ \\ ${ }^{1)}$ Fakultas Teknik Universitas Palangka Raya; ${ }^{2,3)}$ Jurusan Pendidikan Teknik Mesin FT UNY \\ Email: ayaki.tobing@gmail.com
}

\begin{abstract}
The purpose of this research is to find out the feasibility of e-module for discovery learning users' responses to the use of the e-module. This development research follows the development stages of the ADDIE model. Likert scale with four variations of answers was used. Research data were analyzed using a quantitative-descriptive analysis. The result shows that the use of an e-module for discovery learning have met the criteria of feasibility withinthe "very good" category, in terms of content material, learning media, and users' responses. The research findings shows the following results: the assessment of the e-module by the content material experts was in the category of "very good" with a 95 feasibility percentage; the assessment by the media experts was in the category of "very good" with a 82.86 feasibility percentage; teachers' and students' responses to the e-module were in the category of "very good" with 84.38 and 81.67 feasibility percentages, respectively.
\end{abstract}

Keywords: shaft, module, Vocational School

\begin{abstract}
ABSTRAK
Tujuan penelitian secara umum adalah mengembangkan e-modul untuk discovery learning pada materi tegangan dan poros, dan tujuan khususnya adalah untuk mengetahui kelayakan $e$-modul untuk discovery learning dan respon penggunanya. Penelitian pengembangan ini mengikuti model ADDIE. Skala Likert dengan empat variasi jawaban digunakan dalam penelitian ini. Data penelitian dianalisis dengan deskriptif kuantitatif. Hasil penelitian menunjukkan produk e-modul untuk discovery learning pada materi tegangan dan poros telah memenuhi kriteria kelayakan dari segi materi, media maupun dari respon pengguna dengan kategori "sangat baik". Data penelitian menunjukkan bahwa ahli materi diperoleh penilaian e-modul dengan kategori "sangat baik" dengan persentase kelayakan sebesar 95\%, dari ahli media diperoleh penilaian dengan kategori "sangat baik "dengan persentase kelayakan sebesar $82,86 \%$. Di samping itu, respon pengguna terhadap e-modul dalam hal ini guru dan siswa diperoleh kategori "sangat baik" dengan persentase kelayakan masing-masing adalah 84,38\% dan $81,67 \%$.
\end{abstract}

Kata kunci: poros, modul, Sekolah Kejuruan

\section{PENDAHULUAN}

Sekolah Menengah Kejuruan (SMK) dalam mencapai tujuan pendidikan mempunyai ciri khas yang membedakannya dari sekolah pada umumnya yaitu terdapat mata pelajaran produktif atau praktek selain teori yang berfungsi membekali peserta didik agar memiliki keahlian sesuai dengan Standar Kompetensi Kerja Nasional Indonesia (SKKNI) atau standar kompetensi yang disepakati oleh lembaga yang mewakili dunia usaha atau industri. 
Banyak usaha yang telah dilakukan untuk mencapai tujuan pendidikan SMK baik dalam revitalisasi maupun pengembangan kurikulumnnya. Penerapan kurikulum 2013 di SMK telah dimulai pada tahun ajaran 2013/2014 sesuai dengan Permendikbud No 70 Tahun 2013 diharapkan menjadi salah satu solusi untuk mencapai tujuan pendidikan di SMK. Sasaran kurikulum 2013 dalam pembelajaran mencakup tiga ranah yaitu sikap, pengetahuan dan keterampilan yang dipertegas dalam Permendikbud No. 65 Tahun 2013.

Implementasi kurikulum 2013 dengan pendekatan saintifik yang dipadukan dengan media belajar yang melibatkan teknologi yang efektif dalam kenyataannya masih memiliki beberapa kendala dalam pelaksanaan maupun penerapannya. SMK Negeri 1 Sedayu saat ini menyelenggarakan pembelajaran yang berpedoman pada kurikulum 2013. Mekanika Teknik dan Elemen Mesin merupakan salah satu mata pelajaran yang dipelajari di SMK Negeri 1 Sedayu jurusan Teknik Mesin kelas X. Pembelajaran Mekanika Teknik dan Elemen Mesin membutuhkan media pembelajaran yang dapat membantu siswa dalam pembelajaran dan pemecahan masalah yang berhubungan dengan mata pembelajaran sehingga pembelajaran Mekanika Teknik dan Elemen Mesin dapat secara langsung diamati dan dipahami siswa.

Kegiatan menemukan dan memecahkan masalah dalam bentuk penelitian dan eksperimen langsung mengakibatkan peserta didik sangat tidak mungkin mengingat keterbatasan sarana dan prasarana. Hal ini diketahui berdasarkan angket need assessment yang diisi dan wawancara langsung terhadap guru mekanika teknik dan elemen mesin, permasalahan pembelajaran Mekanika Teknik dan Elemen Mesin di SMK Negeri 1 Sedayu diantaranya adalah kurangnya dukungan sumber belajar, metode yang digunakan kurang mendukung keaktifan siswa. Disamping itu, media yang digunakan belum menunjang kegiatan pembelajaran, siswa kesulitan memahami materi yang diberikan. Untuk menelusuri lebih jauh penyebab kurangnya perhatian siswa dalam pembelajaran mekanika teknik dan elemen mesin maka dilakukan penyebaran angket kepada siswa kelas $\mathrm{X}$ yang terdiri dari 25 partisipan.

Data dari penyebaran angket need assessment menunjukkan materi tegangan dan materi poros merupakan materi yang dianggap sulit oleh siswa pada pelajaran Mekanika Teknik dan Elemen Mesin. Sebanyak 40\% siswa menjawab tegangan merupakan materi yang susah dipahami, kemudian sebanyak $44 \%$ dari siswa menjawab poros merupakan materi yang susah dipahami.

Discovery learning merupakan salah satu model pembelajaran yang mampu mendorong keaktifan siswa, kemandirian untuk menemukan sendiri konsep-konsep maupun prinsip-prinsip dalam pembelajaran. "Pembelajaran discovery learning adalah suatu model untuk mengembangkan cara belajar siswa aktif dengan menemukan sendiri, menyelidiki sendiri, maka hasil yang diperoleh akan setia dan tahan lama dalam ingatan, tidak akan mudah dilupakan siswa" (Hosnan, 2014: 282). Selain itu discovery learining juga menjadi salah satu model pembelajaran dengan pendekatan saintifik yang sangat dianjurkan dalam pelaksanaan kurikulum 2013.

Penerapan pembelajaran dengan discovery learning harus didukung oleh media atau alat pembelajaran yang tepat demi menunjang tercapainya tujuan pembelajaran. Joolingen, (2007) mengatakan bahwa :"In supporting discovery learning, cognitive tools may play an important role. Learning processes in discovery may be very complex and all kinds of problems for learners with discovery processes have been observed". Emodul merupakan media pembelajaran yang didesain untuk membantu agar siswa mampu belajar mandiri. E-modul merupakan kolaborasi modul cetak dengan teknologi yang sangat cocok untuk pembelajaran discovery learning karena e-modul cocok digunakan untuk pembelajaran aktif dan merupakan sumber belajar yang cocok dengan kebutuhan 
dan karakter siswa (Hamdani, 2010). Modul memiliki sifat self contained, artinya dikemas ke dalam satu kesatuannyang utuh untuk mencapai kompetensi tertentu. Modul memiliki sifat membantu dan menunjang pembelajaran mandiri (self instructional) dan tidak bergantung pada media atau bahan ajar lain (stand alone) dalam penggunaanya (Anwar, 2010). E-modul juga sangat mendukung pembelajaran discovery learning karena sama-sama memiliki sifat pembelajaran mandiri.

Salah satu perangkat elektronik yang bisa digunakan sebagai wadah untuk e-modul adalah ponsel pintar android. Smartphone android dapat digunakan sebagai media penyampaian pembelajaran yang interaktif atau yang sering disebut mobile learning. Beberapa studi tentang kelebihan smartphone sebagai media pembelajaran yaitu oleh Wen-Chunm Wu \& Yeng-Hong Perng (2016) dalam Research on the Correlations among Mobile Learning Perception, Study Habits, and Continuous Learning menunjukkan adanya korelasi yang positif antara pembelajaran yang menggunakan smartphone dengan karakteristik dan kebiasaan peserta didik, menghadirkan kenyamanan, isi yang ringkas, dan memungkinkan peserta didik untuk belajar tanpa dibatasi waktu dan ruang. Penelitian yang dilakukan Alrasheedi, (2015) mengungkapkan mobile learning memberikan pengalaman dalam pembelajaran karena pembelajaran menjadi menarik, meningkat produktivitas, dan adanya akses internet sehingga penggunaan yang efisien dalam proses belajar.

Berdasarkan pemaparan tersebut perpaduan android dan e-modul akan menjadi suatu media pembelajaran yang menunjang kegiatan belajar siswa yang lebih efisien dan efektif. E-modul berbasis android akan lebih menarik minat siswa untuk mempelajari materi yang ada dalam e-modul dikarenakan konten yang menarik serta lebih praktis untuk digunakan. Disamping itu, e-modul disusun berdasarkan sintaks discovery learning shingga siswa lebih termotivasi dalam memecahkan masalah. Dalam pembelajaran dengan discovery learning kemampuan guru juga meningkat dan lebih inovatif dalam hal mempersiapkan pembelajaran (In'am \& Siti, 2016).

Berdasarkan data dan permasalahan tersebut, perlu adanya penelitian Research and Development (R\&D) tentang pengembangan E-modul untuk discovery learning. E-modul tersebut akan dimuat dalam bentuk aplikasi android. Tujuan penelitian ini adalah mengembangkan e-modul untuk discovery learning pada materi tegangan dan poros, dan tujuan khususnya antara lain: (1) mengetahui kelayakan e-modul untuk discovery learning pada materi tegangan dan poros, (2) mengetahui respon pengguna terhadap produk e-modul untuk discovery learning pada materi tegangan dan poros.

\section{METODE}

Penelitian ini merupakan jenis penelitian dan pengembangan (Research and Development). Model yang digunakan adalah model ADDIE. ADDIE merupakan singkatan dari Analysis, Design, Development or Production, Implementation or Delivery and Evaluations. (Dick \& Carey, 2005)

Prosedur pengembangan e-modul mekanika teknik dan elemen mesin untuk discovery learning adalah desain penelitian pengembangan model ADDIE yang terdiri dari langkah-langkah Analysis (Analisis), Design (Desain), Development (Pengembangan), Implementation (Implementasi) dan Evaluations (Evaluasi) yang dapat dilihat pada tabel tahapan pengembangan dalam penelitian ini 
Tabel 1. Rangkuman Aktivitas Pengembangan E-modul

Tahap Pengembangan

Analysis

Design

Design

Development

\begin{tabular}{cl}
\hline & 14. Melakukan perbaikan $e$-modul sesuai saran validator \\
\hline Implementation & $\begin{array}{l}\text { 15. Melakukan penerapan } e \text {-modul berupa uji coba dalam pembelajaran } \\
\text { 16. Pengisisan angket respon siswa dan guru terhadap } e \text {-modul yang } \\
\text { digunakan. }\end{array}$ \\
\hline Evalution & 17. Mengukur nilai $e$-modul berdasarkan respon guru dan siswa
\end{tabular}

Subjek uji coba dalam penelitian ini terdiri dari 2 kelompok subjek. Kelompok pertama adalah subjek uji coba internal yaitu validator instrumen 2 orang, validator $e$-modul 2 orang yaitu ahli materi dan ahli media. Sedangkan kelompok subjek uji coba kedua adalah guru dan siswa jurusan Teknik Pemesinan SMK Negeri 1 Sedayu yang menggunakan e-modul yang dikembangkan. Instrumen yang akan digunakan berupa angket respon terhadap e-modul.

Lembar validasi ahli merupakan angket yang digunakan untuk memperoleh data tentang penilaian dari ahli terhadap e-modul yang dikembangkan. Hasil penilaian ini dijadikan dasar untuk perbaikan produk sebelum diujicobakan. Lembar validasi $e$-modul diisi oleh dosen ahli materi dan ahli media. Lembar validasi e-modul terdiri dari lembar penilaian kelayakan e-modul untuk discovery learning yang disusun menggunakan skala Likert. Penyusunan lembar validitas ini dikembangkan berdasarkan kisi-kisi instrumen penilaian $e$ modul untuk ahli materi dan ahli media.

Instrumen berupa lembar respon uji coba produk digunakan untuk mengetahui respon guru dan peserta didik terhadap e-modul yang dikembangkan. Penyusunan lembar angket respon guru dan peserta didik mengggunakan indikator yang lebih sederhana dibandingkan dengan lembar validasi ahli.

Selanjutnya data dalam penelitian ini dianalisis dengan statistik deskriptif. Statistik deskriptif adalah statistik yang digunakan untuk menganalisa data dengan cara mendeskripsikan atau menggambarkan data yang terkumpul sebagaimana adanya tanpa bermaksud membuat kesimpulan yang berlaku untuk umum atau generalisasi (Sugiyono, 2017: 169). Agar data dapat digunakan sesuai maksud penelitian, maka data kualitatif dikonversikan lebih dahulu berdasarkan bobot skor (satu, dua, tiga, dan empat). Data ini merupakan data kuantitatif selanjutnya dinalisis dengan statistik deskriptif. Skala Likert dengan empat variasi jawaban merupakan skala yang digunakan dalam penelitian ini.

Penelitian ini ditetapkan nilai kelayakan produk minimal "B", dengan kategori "Baik", sebagai hasil penilaian baik dari ahli media, ahli materi maupun siswa. Jika hasil penilaian akhir keseluruhan aspek dengan nilai minimal " $\mathrm{B}$ " (Baik), maka produk hasil pengembangan 
tersebut sudah dianggap layak digunakan sebagai media atau sumber belajar.

Tabel 2. Skor Pernyataan

\begin{tabular}{lcc}
\hline \multicolumn{1}{c}{ Kategori } & \multicolumn{2}{c}{ Pemberian Skor } \\
\cline { 2 - 3 } & $\begin{array}{c}\text { Pernyataan } \\
\text { Positif }\end{array}$ & $\begin{array}{c}\text { Pernyataan } \\
\text { Negatif }\end{array}$ \\
\hline $\begin{array}{l}\text { SB (Sangat } \\
\text { Baik/Sangat } \\
\text { sesuai) }\end{array}$ & 4 & 1 \\
\hline B (Baik /Sesuai) & 3 & 2 \\
\hline C (Cukup Baik) & 2 & 3 \\
\hline $\begin{array}{l}\text { TB (Tidak Baik } \\
\text { / Tidak Sesuai) }\end{array}$ & 1 & 4 \\
\hline
\end{tabular}

Pedoman konversi di atas yang digunakan untuk menentukan kriteria layaktidaknya produk e-modul yang dikembangkan, dikatakan sudah layak sebagai media pembelajaran apabila hasil penilaian uji coba lapangan minimal termasuk dalam kriteria baik (B). Penelitian ini ditetapkan nilai kelayakan produk minimal "B", dengan kategori "Baik", sebagai hasil penilaian baik dari ahli media, ahli materi maupun siswa. Jika hasil penilaian akhir keseluruhan aspek dengan nilai minimal "B" (Baik), maka produk hasil pengembangan tersebut sudah dianggap layak digunakan sebagai media atau sumber belajar.

Tabel 3. Skala Kategori Kelayakan

\begin{tabular}{cc}
\hline Rentang Skor Rata-rata & Kategori \\
\hline $\mathrm{Xi}+(1,5 \mathrm{Sdi}) \leq \mathrm{X} \leq \mathrm{Xi}+(3,0 \mathrm{Sdi})$ & $\begin{array}{c}\text { Sangat } \\
\text { Baik }\end{array}$ \\
\hline $\mathrm{Xi}+(0 \mathrm{Sdi}) \leq \mathrm{X} \leq \mathrm{Xi}+(1,5 \mathrm{Sdi})$ & Baik \\
\hline $\mathrm{Xi}-(1,5 \mathrm{Sdi}) \leq \mathrm{X} \leq \mathrm{Xi}+(0 \mathrm{Sdi})$ & Cukup \\
& Baik \\
\hline $\mathrm{Xi}+(3,0 \mathrm{Sdi}) \leq \mathrm{X} \leq \mathrm{Xi}-(1,5 \mathrm{Sdi})$ & Tidak Baik \\
\hline
\end{tabular}

\section{HASIL DAN PEMBAHASAN}

Produk e-modul tegangan dan poros disusun berdasarkan salah satu pendekatan saintifik sebagai bagian dari ciri kurikulum 2013. E-modul yang dikembangkan disusun berdasarkan pendekatan discovery learning pada materi tegangan poros. E-modul disusun berdasarkan sintaks doscovery learining sehingga merangsang dan menuntun siswa untuk melakukan tahap discovery pada saat menggunakan e-modul. Materi yang disajikan disusun berdasarkan sintaks discovery learning yang terdiri dari stimulation, problem statement, data collection, data processing, verivication, dan generalization seperti pada Tabel 3.

Tabel 3. Fase Pembelajaran Discovery Learning

\begin{tabular}{|c|c|}
\hline Fase-fase & Kegiatan Pembelajaran \\
\hline Stimulation & $\begin{array}{l}\text { Pada setiap pengantar } \\
\text { materi terdapat persoalan } \\
\text { yang mengundang rasa } \\
\text { ingin tahu siswa }\end{array}$ \\
\hline Problem statement & $\begin{array}{l}\text { Persoalan yang terdapat } \\
\text { dalam materi kemudian } \\
\text { dianalisis dan ditentukan } \\
\text { penyebabnya }\end{array}$ \\
\hline Data collection & $\begin{array}{lr}\text { Pada modul } & \text { siswa } \\
\text { diarahkan } & \text { untuk } \\
\text { mengumpulkan data dan } & \text { fakta terkait persoalan, } \\
\text { baik dalam } & \text { diskusi } \\
\text { kelompok maupun latihan } \\
\text { soal (dalam modul } \\
\text { terdapat tugas yang } \\
\text { mengarahkan siswa untuk } \\
\text { diskusi dan menyususn } \\
\text { laporan) }\end{array}$ \\
\hline Data processing & $\begin{array}{l}\text { Data yang diperoleh } \\
\text { kemudian dianalisis, dan } \\
\text { disusun menjadi sebuah } \\
\text { laporan (dalam modul } \\
\text { terdapat tugas yang } \\
\text { mengarahkan siswa untuk } \\
\text { diskusi dan menyususn } \\
\text { laporan) }\end{array}$ \\
\hline Verification & $\begin{array}{lr}\text { Siswa mempresentasekan } \\
\text { hasil diskusi maupun tugas } \\
\text { individu, dan } & \text { guru } \\
\text { mengarahkan, } & \text { guru } \\
\text { menjelaskan } & \text { kembali } \\
\text { setiap materi, } & \text { siswa } \\
\text { megerjakan latihan soal } & \text { son } \\
\text { sebagai bukti } & \text { telah } \\
\text { memahami } & \text { materi } \\
\text { pelajaran. } & \end{array}$ \\
\hline Generalization & $\begin{array}{l}\text { Anak didik menarik } \\
\text { kesimpulan dan dipandu } \\
\text { oleh guru, mengerjakan } \\
\text { soal akhir pada e-modul }\end{array}$ \\
\hline
\end{tabular}

E-Modul yang telah dibuat kemudian divalidasi oleh ahli materi dan ahli media untuk mengetahui kelayakannya. 
Validasi ahli materi bertujuan untuk mengetahui kelayakan $e$-modul dari segi materi yang terdiri dari aspek Self instructional, aspek Self contained, aspek Stand alone, aspek Adaptive dan aspek User friendly. Dari data diperoleh skor total 114 dengan kriteria "sangat baik".

Dari keseluruhan aspek yang dinilai oleh ahli materi disimpulkan bahwa e-modul tegangan dan poros dikategorikan "sangat baik" hal ini dapat dilihat dari 30 butir penilaian diperoleh skor 114 dari skor maksimal 120 dengan presentase kelayakan 95\%, skor minimal 30, rata-rata ideal (Xi) 75 dan simpangan baku ideal (Sbi) 15.

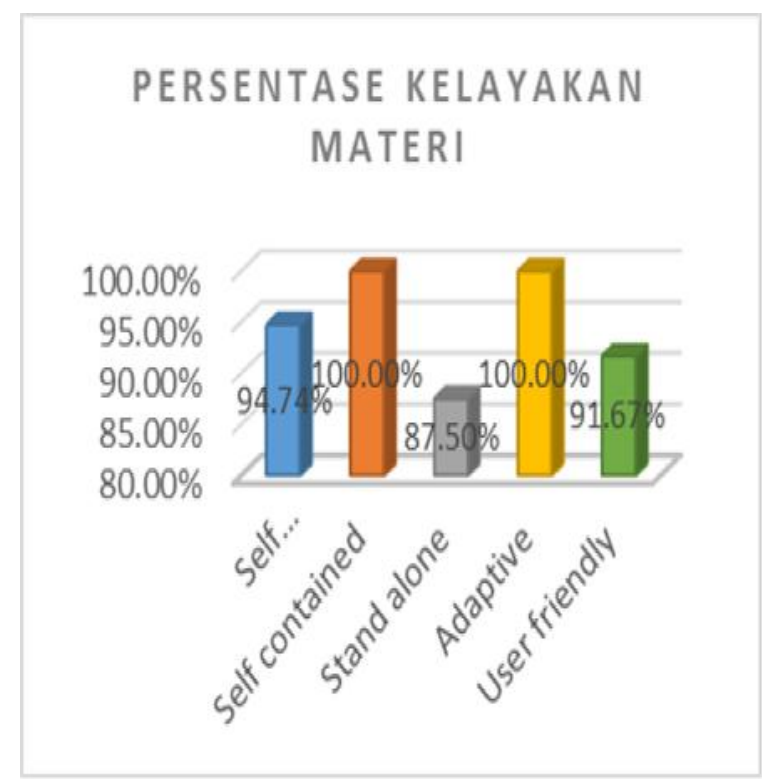

Gambar 1. Grafik Kelayak E-Modul dari Ahli Materi

Validasi ahli media bertujuan untuk mengetahui kelayakan e-modul dari segi media yang terdiri dari aspek verbal, aspek visual, aspek pemrograman dan aspek komponen modul. Dari data keseluruhan aspek diperoleh skor total 116 dengan kriteria "sangat baik".

Dari keseluruhan aspek yang dinilai oleh ahli media disimpulkan bahwa e-modul tegangan dan poros dikategorikan "sangat baik" untuk digunakan hal ini dapat dilihat dari 35 butir penilaian diperoleh skor 116 dari skor maksimal 140 dengan presentase kelayakan $82,86 \%$, skor minimal 35, rata-rata ideal (Xi) 87,5 dan simpangan baku ideal (Sbi) 17,5.

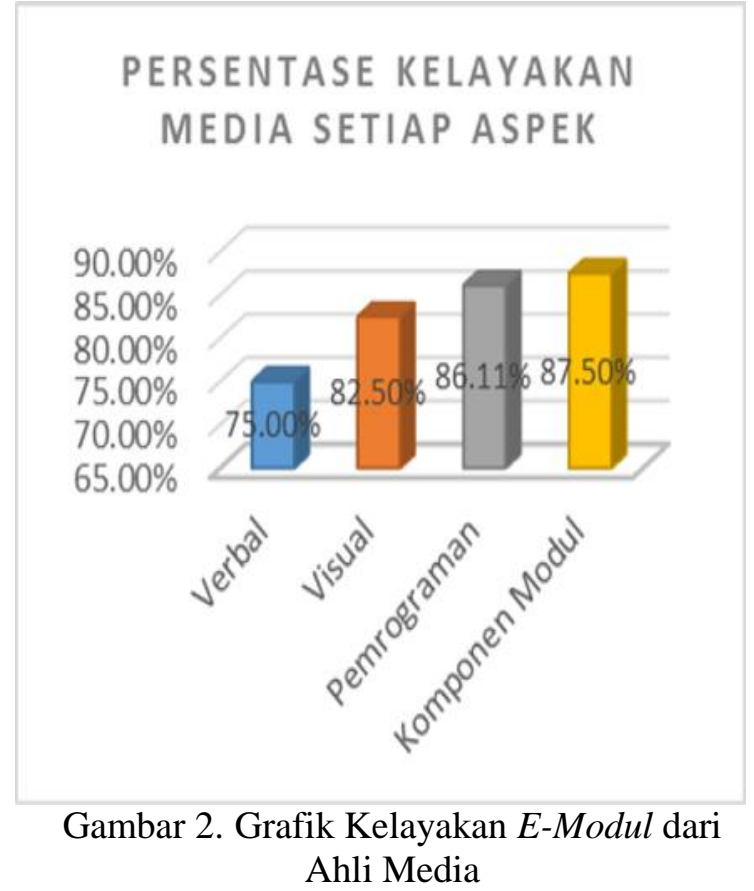

Implementasi dilakukan setelah e-modul dinyakatan layak untuk digunakan oleh ahli materi dan ahli media. Subjek uji coba adalah kelas X kompetensi keahlian teknik pemesinan (TPM) di SMK Negeri 1 Sedayu. Uji coba penggunaan e-modul dilakukan selama 2 kali pertemuan. Implementasi e-modul diakhiri dengan pengisisan angket respon guru dan siswa tentang e-modul mekanika teknik dan elemen mesin yang digunakan selama pembelajaran.

Angket respon guru meliputi aspek materi, aspek media dan aspek kesesuaian terhadap discovery learning. Angket siswa merupakan respon siswa terhadap $e$-modul yang meliputi aspek penyajian materi aspek tampilan, aspek fungsi dan aspek efektivitas.

Dari keseluruhan aspek yang dinilai oleh guru disimpulkan bahwa e-modul tegangan dan poros dikategorikan "sangat baik" untuk digunakan hal ini dapat dilihat dari 40 butir penilaian diperoleh skor 135 dengan skor maksimal 160 dengan presentase kelayakan $84,38 \%$, skor minimal 40 , rata-rata ideal (Xi) 100 dan simpangan baku ideal (Sbi) 20 . 


\section{PERSENTASE RESPON GURU}

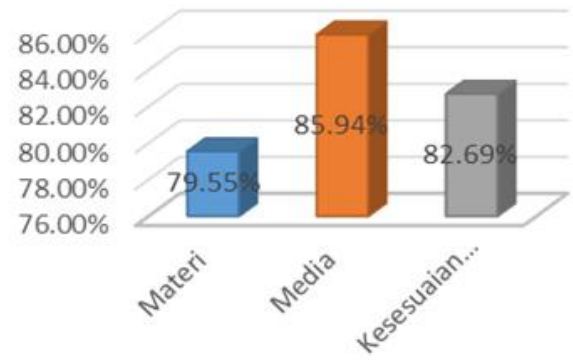

Gambar 3. Grafik Presentasi Respon Guru

Dari keseluruhan aspek respon siswa disimpulkan bahwa e-modul tegangan dan poros dikategorikan "sangat baik" untuk digunakan hal ini dapat dilihat dari 30 butir penilaian diperoleh jumlah skor rata 98 dengan skor maksimal 120 dengan persentase kelayakan $81,67 \%$, skor minimal 30 , rata-rata ideal (Xi) 75 dan simpangan baku ideal (Sbi) 15.

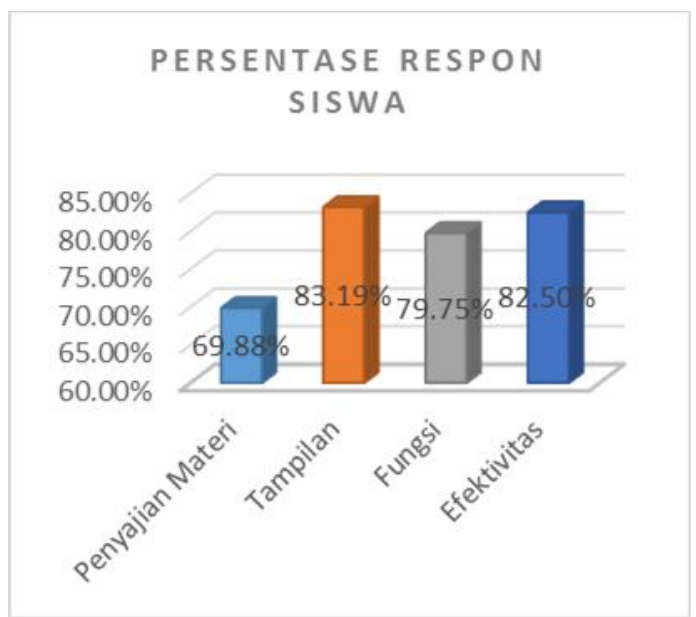

Gambar 4. Grafik Presentasi Respon Siwa

Evaluasi merupakan tahap mereview $e$ modul setelah diimplementasikan. Dari hasil respon guru dan siswa terhadap e-modul mekanika teknik dan elemen mesin yang digunakan diperoleh kesimpulan bahwa $e$ modul tersebut dikategorikan sangat baik. Namun ada beberapa saran dan komentar yang diperoleh dari siswa untuk memperbaiki kualitas $e$-modul seperti mengganti audio dalam $e$-modul yang lebih menarik. Perbaikan $e$-modul yang diperoleh dari respon siswa bersifat tidak urgent namun tetap dipertimbangkan jika saran dan komentar tersebut masih sesuai dengan tujuan memperbaiki kualitas e-modul. Saran juga diperoleh dari guru yaitu berupa harapan untuk mengembangkan e-modul tidak hanya pada KD mendeskripsikan tegangan dan poros melainkan pada mata pelajaran yang lain yang terdapat pada kompetensi keahlian teknik pemesinan.

\section{SIMPULAN}

Berdasarkan hasil penelitian pengembangan $e$-modul tegangan dan poros diperoleh kesimpulan sebagai berikut: (1) Produk e-modul tegangan dan poros telah memenuhi kriteria kelayakan baik dari segi materi maupun dari segi media; (2) Respon pengguna terhadap $e$-modul dalam hal ini guru dan siswa diperoleh dengan kategori "sangat baik".

E-modul tegangan dan poros disusun berdasarkan sintaks discovery learning sebagai bagian dari karakterstik kurikulum 2013 yang memiliki ciri sebagai berikut : (a) modul yang dihasilkan berformat apk dan dapat dioperasikan pada msartphone dengan sistem operasi android; (b) e-modul didesain dengan tampilan yang menarik baik dari segi warna, huruf, animasi, dan gambar karakter; (c) tampilan e-modul disusun berdasarkan karakteristik komponen modul.

\section{DAFTAR RUJUKAN}

Alrasheedi. (2015). A Maturity Model for Mobile Learning. Tesis. The University of Western Ontario.

Anwar, I. (2010). Pengembangan Bahan Ajar. Bahan Kuliah Online. Direktori UPI. Bandung.

Dick, W., Carey, L., \& Carey, J. O. (2005). The systematic design of instruction. Harper Collin College Publisher :Boston.

Hamdani, H. (2010). Strategi Belajar Mengajar. Bandung: CV Pustaka Setia.

Hosnan, M. (2014). Pendekatan Saintifik dan Kontekstual dalam Pembelajaran Abad 21. Bogor: Ghalia Indonesia. 
In'am, A., \& Hajar, S. (2017). Learning Geometry through Discovery Learning Using a Scientific Approach. International Journal of Instruction, 10, 1694-609.

Joolingen, V.W. (2007). Cognitive tools for discovery learning. International Journal of Articial Intelligence in Education, 10, 385-397.

Kementerian Pendidikan dan Kebudayaan. (2013). Peraturan Menteri Pendidikan dan Kebudayaan Nomor 65 Tahun 2013, Tentang Standar Proses Pendidikan Dasar dan Menengah.

Kementerian Pendidikan dan Kebudayaan .(2013). Peraturan Menteri Pendidikan dan Kebudayaan Nomor 70 Tahun 2013, Tentang Kerangka Dasar dan Struktur Kurikulum Sekolah Menengah Kejuruan/Madrasah Aliyah Kejuruan.

Sugiyono. (2017). Metode Penelitian Pendidikan Pendekatan Kuantitatif, Kualitatif, dan R\&D. Bandung: Penerbit Alfabeta.

Wu, Wen-Chun \& Perng, Yeng-Hong. (2016) Research on the Correlations among Mobile Learning Perception, Study Habits, and Continuous Learning, Eurasia Journal of Mathematics, Science \& Technology Education, 12(6), $1665-$ 1673 